Asian-Australasian Journal of

Food Safety and Security

ISSN 2523-1073 (Print) 2523-2983(Online)

www.ebupress.com/journal/aajfss

\title{
Article \\ Organophosphorus pesticide residues detected in eggplant and tomato samples collected from different regions of Bangladesh
}

Md. Sultan Ahmed*, Afroza Begum, Mohammad Dalower Hossain Prodhan, Marina Afroze and Debasish Sarker

Division of Entomology, Bangladesh Agricultural Research Institute, Joydebpur, Gazipur-1701, Bangladesh

*Corresponding author: Md. Sultan Ahmed, Division of Entomology, Bangladesh Agricultural Research Institute, Joydebpur, Gazipur-1701, Bangladesh. E-mail: sultan_palbari@yahoo.com

Received: 01 April 2021/Accepted: 25 May 2021/ Published: 31 May 2021

\begin{abstract}
The study was conducted to detect and quantify the residue of seven commonly used organophosphorus pesticides (acephate, chlorpyrifos, quinalphos, diazinon, malathion, dimethoate and fenitrothion) in eggplant and tomato samples collected from local market of commercially grown four different regions viz. Bogura, Narsingdi, Jeshore and Cumilla for the comparison between the detected residue level with maximum residue limit (MRL) set by European Union. A total of 80 analyzed samples of eggplant and tomato, $21.25 \%$ of the total number of samples contaminated with acephate, chlorpyrifos, fenitrothion and diazinon residues which were above the EU-MRLs. Out of 40 analyzed samples of eggplant, 11 samples were contaminated with acephate, diazinon fenitrothion and chlorpyrifos residues. All of the contaminated samples (27.5\% of the total number of samples) had chlorpyrifos (0.02-0.046), acephate (0.017-0-0.39), diazinon (0.110.47 ) and fenitrothion (0.20) residues which were above the EU-MRLs. The eggplant samples collected from Jeshore and Narsingdi received more pesticides than Cumilla and Bogura regions. In case of 40 analyzed samples of tomato, 6 samples (15\% of the total number of samples) had chlorpyrifos (0.27-0.43), diazinon (0.25) and fenitrothion (0.10) residues which were above EU-MRLs. Malathion, quinalphos and dimethoate residues were not found in any of the tested samples which might be applied at recommended doses.
\end{abstract}

Keywords: organophosphorus pesticide; residue; MRL; eggplant; tomato

\section{Introduction}

Vegetables grown in Bangladesh are very popular to consumers. These are conceded as a source of many nutrients, including potassium, dietary fiber, vitamin A, and vitamin C. Vegetables provide nutrients vital for health and maintenance of human body. Eating a diet rich in vegetables and fruits as part of an overall healthy diet may reduce risk for heart disease, including heart attack and stroke (USDA, 2021). It has been reported that in eggplant and tomato the attack of insect pests are severe and farmers sprayed insecticides quite frequently even every day (Anonymous, 2001). One potential drawback associated with a shift toward more intensive vegetable production is the common reliance of most vegetable producers on heavy application of pesticide (Hossain et al., 2000).

The development of the agriculture, the enlargement of the agricultural boundaries, the improvement of the food production technology and mainly the demands of the new markets for better products both in quality and quantity has been made among others with intensive uses of pesticides for productivity warranty (Trevisan $e t$ al., 2004). Pesticide being toxic can become a potential hazard to the manufacturers, the user, the public at large and the environment. Pesticide can produce negative impacts, both social and private (Antle and Pingali, 1994). The indiscriminate use of pesticide has caused in contamination of our food, water and air. At present, pesticide residue in food has become a consumers safety issue. But very little references are available on the presence of pesticides in vegetables in Bangladesh (Khatoon et al., 2004; Ahmed et al., 2013; Akter et al., 2017; Ahmed et 
al., 2020). The present study was undertaken to detect and quantify the amount of left over residue of seven organophosphorus pesticides in eggplant and tomato collected from local market of four different regions of Bangladesh.

\section{Methods and Materials}

The standard for chlorpyrifos, quinalphos, acephate, dimethoate, diazinon, malathion, and fenitrothion were obtained from Sigma-Aldrich Laborchemikalien, Seelze, Germany via Bangladesh Scientific Pvt. Itd. Dhaka, Bangladesh. Standards of all the pesticides contained $>99.6 \%$ purity. Available vegetable samples of eggplant and tomato were collected from local market of four different regions namely Jeshore, Cumilla, Narsingdi and Bogura.

\subsection{Extraction, separation and cleanup}

The collected vegetable samples ( $\geq 250 \mathrm{~g}$ ) were grounded thoroughly with the meat grinder (Handmixer M-122, Bamix, Switzerland) that was randomly taken from $1 \mathrm{Kg}$ of stored samples. A sub sample of $20 \mathrm{~g}$ was taken into a wide mouth jar then $100 \mathrm{ml}$ of hexane was added to it. Anhydrous sodium sulphate $\left(\mathrm{Na}_{2} \mathrm{SO}_{4}\right)$ was also added with sample until water was removed from the sample. The mixture was then macerated with high-speed homogenizer (Ultraturax, IKA T18 basic, Germany) for 2 minutes. The homogenized material were then poured into $250 \mathrm{ml}$ conical flask and placed into shaker (Orbital Shaking Incubator, Rexmed, Sweden) for 12hrs continuous shaking. After shaking, the slurry was filtered through a Buchner funnel with suction. The flask and filter cakes were rinsed with $25 \mathrm{ml}$ of hexane each. The filtrate was then transferred into $250 \mathrm{ml}$ round bottom flask and was dried to $3-5 \mathrm{ml}$ by evaporation using a rotary vacuum evaporator (Laborota-4001, Heidolph, Germany). The concentrated filtrate was then transferred into volumetric flask making $10 \mathrm{ml}$ in volume. For colour removal, $20 \mathrm{ml}$ methanol was added with $10 \mathrm{ml}$ filtrate and shaked vigorously for 3-5 minutes. After shaking, the separatory funnel was set on stand and kept undisturbed for 3-5 minutes. Then the clear part of the solution from the bottom of the separatory funnel was collected in vial which was then centrifuged at $1200 \mathrm{rpm}$ for 5minutes (Laboratory Centrifuges, Sigma-3K30, Germany). After centrifuge, supernatant was collected for injection. Prior to the injection, this volume was again cleaned up by HPLC filter (0.2PTFE) which was ready for injection in Gas Chromatography.

\subsection{Detection and quantification of pesticide residue in samples}

The concentrated extracts were analyzed by GC-2010 (Shimadzu) with Flame Thermionic Detector (FTD) for detection of seven organophosphorus pesticides (acephate, diazinon, fenitrothion, malathion, quinalphos, dimethoate and chlorpyrifos). The capillary column used was AT-1, length $30 \mathrm{~m}$, ID $0.25 \mathrm{~mm}$ and film thickness $0.25 \mu \mathrm{m}$ in case of both detectors. Helium was used as carrier and make up gas in FTD. The instrument parameters for GC-FTD were as follows: Injection port temperature was $250^{\circ} \mathrm{C}$, Column oven initial temperature was $150^{\circ} \mathrm{C}$ which went up to $220^{\circ} \mathrm{C}$ following $10 \mathrm{~min}$ incremental time. Detector temperature was $280^{\circ} \mathrm{C}$, Stop time: $10 \mathrm{~min}$, Current: $1.0 \mathrm{pA}$, Makeup flow: $30 \mathrm{ml} / \mathrm{min}, \mathrm{H}_{2}$ Flow: $1.5 \mathrm{~mL} / \mathrm{min}$ and Air flow: 145 $\mathrm{ml} / \mathrm{min}$.

Prior to the injection of the sample extract, standard solutions of different concentrations of each pesticide were prepared and injected with selected instrument parameters. The samples were calibrated (retention time, peak area etc.) against four pointed calibration curve of standard solution of concerned pesticide. Each peak was characterized by its retention time. Sample results were expressed in $\mathrm{mg} / \mathrm{Kg}$ automatically by the GC software which represented the concentration of the final volume injected. From this value, the actual amount of pesticide residue present in the sample was determined by using the following formula:

Residue in sample $(\mathrm{mg} / \mathrm{Kg})$

Conc. obtained in injected volume $(\mathrm{mg} / \mathrm{Kg}) \mathrm{X}$ Quantity of final volume $(\mathrm{L})$

Amount of sample taken $(\mathrm{Kg})$ 


\section{Results}

The analytical results of the eggplant and tomato for the detection of pesticide residue are summarized in Tables 1 and 2 .

Table 1. Residue levels $(\mathrm{mg} / \mathrm{Kg})$ found in eggplant collected from markets of different regions of Bangladesh.

\begin{tabular}{|c|c|c|c|c|c|}
\hline Locations & $\begin{array}{l}\text { Samples } \\
\text { analyzed }\end{array}$ & $\begin{array}{l}\text { Contaminated } \\
\text { samples }\end{array}$ & $\begin{array}{l}\text { Detected } \\
\text { Pesticide }\end{array}$ & $\begin{array}{l}\text { Residue levels } \\
\text { (mg/Kg) }\end{array}$ & $\begin{array}{l}\text { EU MRLs } \\
(\mathbf{m g} / \mathbf{K g})\end{array}$ \\
\hline \multirow[t]{3}{*}{ Jeshore } & \multirow[t]{3}{*}{10} & \multirow[t]{3}{*}{5} & Acephate & $0.05,0.39$ & 0.01 \\
\hline & & & Diazinon & $0.11,0.33$ & 0.01 \\
\hline & & & Chlorpyrifos & 0.46 & 0.01 \\
\hline \multirow[t]{3}{*}{ Narsingdi } & \multirow[t]{3}{*}{10} & \multirow[t]{3}{*}{3} & Acephate & 0.17 & 0.01 \\
\hline & & & Diazinon & 0.47 & 0.01 \\
\hline & & & Fenitrothion & 0.21 & 0.01 \\
\hline \multirow[t]{2}{*}{ Cumilla } & \multirow[t]{2}{*}{10} & \multirow[t]{2}{*}{2} & Acephate & 0.04 & 0.01 \\
\hline & & & Chlorpyrifos & 0.02 & 0.01 \\
\hline \multirow[t]{2}{*}{ Bogura } & \multirow[t]{2}{*}{10} & \multirow[t]{2}{*}{2} & Chlorpyrifos & 0.42 & 0.01 \\
\hline & & & Diazinon & 0.37 & 0.01 \\
\hline Total & 40 & 11 & - & - & - \\
\hline
\end{tabular}

Among the 40 analyzed eggplant samples, 11 were (27.50\% of the total number of samples) contaminated with acephate, diazinon fenitrothion and chlorpyrifos residues. All of the detected quantities of chlorpyrifos $(0.02-$ 0.046), acephate (0.017-0-0.39), diazinon (0.11-0.47) and fenitrothion (0.20) residues were above the EUMRLs. Among the four locations Jeshore and Narsingdi received more pesticide residues than Cumilla and Bogura. The eggplant samples of Cumilla had fewer residues in compare to other locations. The results of the study agreed with the works of Aktar et al. (2017), they found out of fifty samples of eggplant collected from Mymensingh, eleven (22\%) were contaminated by chlorpyrifos, diazinon, dimethoate and quinalphos of which five contained residue above the EU-MRL.

Table 2. Residue levels $(\mathrm{mg} / \mathrm{Kg})$ found in tomato collected from markets of different regions of Bangladesh.

\begin{tabular}{|l|l|l|l|l|l|}
\hline Location & $\begin{array}{l}\text { Samples } \\
\text { analyzed }\end{array}$ & $\begin{array}{l}\text { Contaminated } \\
\text { samples }\end{array}$ & $\begin{array}{l}\text { Detected } \\
\text { Pesticide }\end{array}$ & $\begin{array}{l}\text { Residue levels } \\
(\mathbf{m g} / \mathbf{K g})\end{array}$ & $\begin{array}{l}\text { EU MRLs } \\
(\mathbf{m g} / \mathbf{K g})\end{array}$ \\
\hline Jeshore & 10 & 1 & Chlorpyrifos & 0.27 & 0.01 \\
\hline Nasingdi & 10 & 1 & Chlorprifos & 0.38 & 0.01 \\
\hline Cumilla & 10 & 2 & Chlorpyrifos & 0.43 & 0.01 \\
\cline { 4 - 6 } & & & Diazinon & 0.25 & 0.01 \\
\hline \multirow{2}{*}{ Bogura } & \multirow{2}{*}{10} & 2 & Fenitrothion & 0.10 & 0.01 \\
\hline Total & 40 & 6 & Chlorpyrifos & 0.28 & 0.01 \\
\hline
\end{tabular}

Among 40 analyzed samples of tomato, 6 samples (15\% of the total number of samples) were contaminated with chlorpyrifos (0.27-0.43), diazinon (0.25) and fenitrothion (0.10) residues. All of the contaminated samples had residue which were EU-MRLs. Among the four locations Cumilla and Bogura had more pesticide residues than Narsingdi and Jeshore. Bagura had 10 time's higher fenitrothion and 28 time's higher chlorpyrifos residue than corresponding MRL value. On the other hand Cumilla showed 43 time's higher chlorpyrifos and 25 time's higher diazinon residue than EU-MRL. The results can be compared with Ahmed et al. (2016), they found $18.26 \%$ vegetable (31 of 170) samples (tomato, brinjal, hyacinth bean, cabbage, bitter gourd, pointed gourd, snake gourd, okra and yard long bean) contained four insecticides (chlorpyrifos, quinalphos, acephate and cypermethrin) which were above MRL collected from 8 different regions of Bangladesh. 


\section{Discussion}

A total of 40 analyzed samples of eggplant (brinjal) were collected from local market of commercially grown four locations i.e., Bagura, Narsingdi, Cumilla and Jeshore. The results revealed that 11 samples $(27.50 \%$ of the total number of samples) contaminated with fenitrothion (0.20), diazinon (0.11-0.47), acephate (0.017-0-0.39) and chlorpyrifos (0.02-0.046) residues which were above the MRLs provided by European Union. Among the four locations Jeshore and Narsingdi had more pesticide residues than Cumilla and Bogura regions. Jeshore showed 11 to 33 times higher diazinon, 5 to 39 times higher acephate and 46 times higher chlorpyrifos residue than EU-MRLs and Narsingdi had 17 times higher acephate, 21 times higher fenitrothion and 47 times higher diazinon residue than EU-MRLs. The eggplant sample of Cumilla had fewer residues than other three locations. In case of tomato, out of 40 analyzed samples, 6 samples (15\% of the total number of samples) were contaminated with chlorpyrifos (0.27-0.43), diazinon (0.25) and fenitrothion (0.10) residues and all of the quantities were above EU-MRLs. Among the four locations Cumilla and Bogura had little more residues than Narsingdi and Jeshore. Bogura had 10 time's higher fenitrothion and 28 time's higher chlorpyrifos residue than EU-MRLs. But Cumilla had 43 time's higher chlorpyrifos and 25 time's higher diazinon residue than EUMRLs. Repeated use of pesticides in vegetables might cause the higher level of residues even at above MRL (Anonymous, 2001). These results can be compared with Virgina and Bajet (1996), they found residue of ogranophosphorus pesticides (e.g. methomyl, triazophos, methyl parathion and diazinon) using rapid field kit from market basket samples of eggplant, tomato, cabbage and chinese peachy that exceeded MRL. Ahmed et al. (2013) found $38.67 \%$ brinjal samples were contaminated with six insecticides (viz., acephate, fenitrotion, quinalphos, cypermethrin, diazinon and malathion), of which $17.33 \%$ samples had residue above MRL irrespective of single or multiple residues. According to Islam et al. (2014) out of seventy eight samples of eggplant, eight samples $(11.5 \%)$ were contaminated by organophosphorus (chlorpyrifos, diazinon and dimethoate) residues and two of them had dimethoate residue which were exceeded the MRL. Hossain et al. (2014) reported that, organophosphorus pesticides as acephate, chlorpyrifos, ethion, fenitrothion, parathion and malathion were detected in the 10 samples out of 15 tested samples of tomato, brinjal and lady's finger collected from Savar bazaar. Most of the pesticides were found at higher levels than their corresponding MRLs values in all vegetable samples except chlorpyrifos in tomato and lady's finger. Alam et al. (2015) found 50\% samples contained pesticide residue and the levels of all the samples were above the EU-MRL collected from Narayanganj. Ahmed et al. (2016a) found 23.40\% samples (11 of 47) of cauliflower and yard long bean had insecticide residues (quinalphos, malathion, diazinon, fenitrothion and cypermethrin) exceeded the MRL level collected from 8 different locations (viz. Bogura, cumilla, Dhaka, Gazipur, Jeshore, Khagrachari, Rajshahi and Rangpur) of Bangladesh. Ahmed et al. (2018) stated that 13.33\% cauliflower samples (10 of 75) had residues exceeding the MRL irrespective of single or multiple insecticide residues (acephate, fenitrothion, quinalphos and cypermethrin) collected from Jeshore, Gazipur and Rangpur regions. In another study of Ahmed et al. (2019), they found among 72 analyzed samples of eggplant and hyacinth bean, $12.5 \%$ of the total number of samples contaminated with chlorpyrifos, dimethoate and quinalphos residues which were above EU-MRLs. The results of the present study agreed with the works of the above authors from home and abroad.

\section{Conclusions}

Among 80 analyzed samples of eggplant and tomato, $21.25 \%$ of the total number of samples contaminated with acephate, chlorpyrifos, fenitrothion and diazinon residues which were above the EU-MRLs. Among 17 contaminated samples, 11 samples of eggplant $(27.50 \%)$ contained with fenitrothion, diazinon, chlorpyrifos and acephate residues and 6 samples of tomato (15\%) had chlorpyrifos, diazinon and fenitrothion residues and all of the detected levels were above EU-MRLs in both the vegetables. Therefore, these vegetables might not be safe for consumption before getting other decontamination options. So, more efforts in pesticide research are needed for safe food production and marketing.

\section{Conflict of interest}

None to declare.

\section{References}

Ahmed MS, A Begum and D Sarker, 2020. Determination of pre-harvest interval for dimethoate and quinalphos in selected vegetables. Asian Australas J. Biosci. Biotechnol., 5: 42-47.

Ahmed MS, A Begum, MDH Prodhan and D Sarker, 2019. Analysis of pesticide residue in vegetables collected from nine different regions of Bangladesh using Gas Chromatography. Asian Australas J. Food Saf. Secur., 3: 23-26. 
Ahmed MS, MA Sardar, M Ahmad and KH Kabir, 2018. Qualitative analysis of insecticide residue in cauliflower samples collected from different regions of Bangladesh. Asian Australas J. Food Saf. Secur., 2: 29-34.

Ahmed MS, MD Rahman, A Begum, AZ Chowdhury and MS Reza, 2016. Multi insecticide residue analysis in vegetables collected from different regions of Bangladesh. Asian Australas J. Biosci. Biotechnol., 1: 545549.

Ahmed MS, A Begum, MD Rahman, MW Akon and MAZ Chowdhury, 2016a. Extend of insecticide residue load in vegetables grown under conventional farming in Bangladesh. The Agriculturists, 14: 38-47.

Ahmed MS, MA Sardar, M Ahmad and KH Kabir, 2013. Determination of pyrethroid and organophosphorus insecticide residue in brinjal samples collected from some selected regions of Bangladesh. Bangladesh J. Entomol., 23: 39-51.

Aktar MA, R. Khatun, MDH Prodhan. 2017. Determination of pesticide residues in eggplant using modified QuEChERS extraction and Gas Chromatography. Int. J. Agron. Agri. R., 11: 22-31.

Alam MN, MAZ Chowdhury, MS Hossain, MM Rahman, MA Rahman, SH Gan and MI Khalil, 2015. Detection of residual levels and associated health risk of seven pesticides in fresh eggplant and tomato samples from Narayanganj District, Bangladesh. Journal of Chemistry, 1-7.

Anonymous, 2001. Coordinated research on insecticide residue and resistance in major vegetables grown in Bangladesh. Report on Contact Research Project, BARC, BARI, Joydebpur, Gazipur, 102 p.

Antle JM and PL Pingali, 1994. Pesticides, Productivity, and Farmer Health: A Philippine Case Study, American Journal of Agril. Economics, 76: 418-430.

EU pesticides database. http://ec.europa.eu/food/plant/pesticides/eu-pesticides-data base. Accessed 10 March 2021.

Hossain MS, ANM Fakhruddin, MAZ Chowdhury, MA Rahman and MK Alam, 2014. Health risk assessment of selected pesticide residues in locally produced vegetables of Bangladesh, Int. Food Res. J., 22: 110-115.

Islam MW, KM Golam Dastogeer, I Hamim, MDH Prodhan, M Ashrafuzzaman, 2014. Detection and quantification of pesticide residues in selected vegetables of Bangladesh. Journal of Phytopathology and Pest Management, 1: 17-30.

Khatoon JA, MS Islam, NM Talukder and MA Hossain, 2004. Monitoring the residue level of three selected pesticides in Red Amaranth, J. Biol. Sci., 4: 474-479.

Trevisan MJ, GC BAPTISTA, LR P Trevizan and G Papa, 2004. Residue of carbosulfan and its carbofuran metabolites and 3-hydroxy-carbofuran in oranges. Rev. Bras. Frutic., 26(2), https://doi.org/10.1590/S010029452004000200012.

U. S. Department of Agriculture, Washington D C. Dietary Guidelines for Americans, 2020-2025. Why is it important to eat vegetables? https://www.myplate.gov/eat-healthy/vegetables (Accessed 10 March 2021).

Virgina RO and CM Bajet, 1996. Pesticides in the Philippine environment. In: Proceedings. Anniversary and Annual Scientific Meeting, (Dizon, TD, Eusebio JE, Duenas JN, Palis FV and Mabbayad MO eds.). Pest Management Council of the Philippine, Davao City, pp. 61-77. 